\title{
Impact of Mitral Regurgitation and Myocardial Viability on Left Ventricular Reverse Remodeling After Cardiac Resynchronization Therapy in Patients With Ischemic Cardiomyopathy
}

\author{
Mario Sénéchal, $\mathrm{MD}^{\mathrm{a}}{ }^{*}$, Patrizio Lancellotti, $\mathrm{MD}^{\mathrm{b}}$, Julien Magne, $\mathrm{PhD}^{\mathrm{b}}$, Patrick Garceau, $\mathrm{MD}^{\mathrm{a}}$, \\ Jean Champagne, MD ${ }^{\mathrm{a}}$, François Philippon, MD ${ }^{\mathrm{a}}$, Gilles O'Hara, MD ${ }^{\mathrm{a}}$, Marie Moonen, MD ${ }^{\mathrm{b}}$, and \\ Michelle Dubois, $\mathrm{BSc}^{\mathrm{a}}$
}

\begin{abstract}
This study investigated the impact of ischemic mitral regurgitation (MR) severity and viability on left ventricular (LV) reverse remodeling after cardiac resynchronization therapy (CRT) in patients with ischemic cardiomyopathy. Severe MR and ischemic cardiomyopathy have been associated with lack of LV reverse remodeling after CRT. Fifty-seven consecutive patients with ischemic MR, LV ejection fraction $\leq 35 \%$, QRS duration $\geq 120$ $\mathrm{ms}$, and intraventricular dyssynchrony $\geq 50 \mathrm{~ms}$ were prospectively included. Stress echocardiography was performed before CRT implantation. Viability in the region of the LV pacing lead was defined as the presence of viability in 2 contiguous segments. Response to CRT at 6 months was defined by evidence of $\geq 15 \% \mathrm{LV}$ decrease in end-systolic volume. Severe MR was defined by an effective regurgitant orifice (ERO) area $\geq 20 \mathrm{~mm}^{2}$. Thirtythree patients (58\%) were responders at follow-up. Baseline ERO area and prevalence of severe MR were not different between responders and nonresponders (19 \pm 11 vs $21 \pm 13$ $\mathrm{mm}^{2}, \mathrm{p}=0.67 ; 52 \%$ vs $53 \%, \mathrm{p}=0.84$ ). In responders, MR was decreased by $58 \%$ (ERO $19 \pm$ 12 to $\left.8 \pm 6 \mathrm{~mm}^{2}\right)$. In the presence of viability in the region of the pacing lead, $74 \%(\mathrm{n}=29$ patients) were responders (sensitivity $88 \%$, specificity $58 \%$ ); in the subgroup of patients with viability in the region of the pacing lead and severe MR, $83 \%(n=17$ patients) were responders. In conclusion, $\mathrm{LV}$ remodeling is frequent and ischemic MR decrease important in patients with viability in the region of the pacing lead without regard to MR severity. ㅇ 2010 Elsevier Inc. All rights reserved. (Am J Cardiol 2010;106:31-37)
\end{abstract}

Ischemic heart disease is the most common cause of systolic left ventricular (LV) dysfunction. The prognosis of these patients is particularly modulated by the extent of residual viable myocardium. Cardiac resynchronization therapy (CRT) improves LV function and geometry, exercise capacity, and outcomes of appropriately selected patients with heart failure. ${ }^{1-3}$ CRT leads to a decrease in mitral regurgitation (MR) severity at rest and during exercise by an increase of LV function and local synchronicity (decrease in mechanical activation delay of papillary muscles). ${ }^{4-11} \mathrm{Re}-$ sponse to CRT largely depends on extent of LV dyssynchrony, severity of LV remodeling, extent of scar tissue, and possibility offered to the left ventricle to recruit function (contractile reserve). Whether the presence of MR and its severity could modulate the response to CRT is still controversial. Several investigators have suggested that extent of $\mathrm{LV}$ reverse remodeling could be lessened in patients with significant MR, particularly in the setting of ischemic car-

\footnotetext{
${ }^{a}$ Department of Cardiology, Institut Universitaire de Cardiologie et de

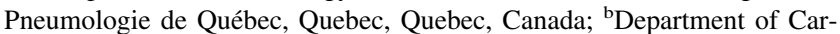
diology, University Hospital, Sart Tilman, Liège, Belgium. Manuscript received January 19, 2010; revised manuscript received and accepted February 7, 2010.

Dr. Sénéchal received a grant from Institut de Cardiologie de Québec, Quebec, Quebec, Canada.

*Corresponding author: Tel: 418-656-8711; fax: 418-656-4581.

E-mail address: mario.senechal@criucpq.ulaval.ca (M. Sénéchal).
}

diomyopathy. ${ }^{12-14}$ This study investigated the potential impact of MR severity and myocardial contractile reserve on acute and long-term responses to CRT in patients with ischemic cardiomyopathy and significant LV dyssynchrony.

\section{Methods}

From May 2005 to March 2008, 57 patients (mean age $71 \pm 8$ years, 43 men, $(75 \%)$ were prospectively enrolled in the Institut Universitaire de Cardiologie et de Pneumologie de Québec, Quebec, Canada $(\mathrm{n}=34)$ and the University Hospital of Sart Tilman, Liège, Belgium $(n=23)$. Inclusion criteria were (1) New York Heart Association functional class III and IV heart failure; (2) QRS duration $\geq 120 \mathrm{~ms}$; (3) persistent LV systolic dysfunction (LV ejection fraction $\leq 35 \%$ ); (4) ischemic cardiomyopathy; (5) basal LV dyssynchrony $\geq 50 \mathrm{~ms}$; (6) optimal medical treatment for heart failure including angiotensin-converting enzyme inhibitors or angiotensin receptor blocker antagonists diuretics, $\beta$-receptor blockers, and spironolactone when tolerated; and (7) sinus rhythm. Patients with recent myocardial infarction or coronary revascularization ( $<6$ months) and presenting standard contraindications to stress echocardiography were excluded. All patients underwent coronary angiography before implantation to exclude treatable ischemic heart disease. The cause was considered ischemic in the presence of significant coronary artery disease ( $\geq 50 \%$ stenosis in $\geq 1$ of the major epicardial coronary arteries) and/or a history of 
Table 1

Demographic and clinical data

\begin{tabular}{|c|c|c|c|c|}
\hline Variables & $\begin{array}{l}\text { All Patients } \\
\quad(\mathrm{n}=57)\end{array}$ & $\begin{array}{c}\text { Responders } \\
(\mathrm{n}=33,58 \%)\end{array}$ & $\begin{array}{l}\text { Nonresponders } \\
(\mathrm{n}=24,42 \%)\end{array}$ & $\mathrm{p}$ Value \\
\hline Age (years) & $71 \pm 8$ & $71 \pm 9$ & $71 \pm 8$ & 0.90 \\
\hline Men & $43(75 \%)$ & $24(73 \%)$ & $9(38 \%)$ & 0.58 \\
\hline QRS duration (ms) & $162 \pm 28$ & $166 \pm 30$ & $157 \pm 25$ & 0.22 \\
\hline Left bundle branch block & $27(47 \%)$ & $14(42 \%)$ & $13(54 \%)$ & 0.38 \\
\hline Right bundle branch block & $4(7 \%)$ & $3(9 \%)$ & $1(4 \%)$ & 0.46 \\
\hline Intraventricular conduction delay & $19(33 \%)$ & $10(30 \%)$ & $9(37 \%)$ & 0.57 \\
\hline PR interval (ms) & $189 \pm 42$ & $185 \pm 38$ & $193 \pm 47$ & 0.5 \\
\hline Pacing before cardiac resynchronization therapy & $7(12 \%)$ & $6(18 \%)$ & $1(4 \%)$ & 0.09 \\
\hline New York Heart Association class III/IV & $42(74 \%) / 15(26 \%)$ & $25(76 \%) / 8(24 \%)$ & $17(71 \%) / 7(29 \%)$ & 0.68 \\
\hline \multicolumn{5}{|l|}{ Medications } \\
\hline Diuretic & $54(95 \%)$ & $31(94 \%)$ & $23(96 \%)$ & 0.75 \\
\hline$\beta$ blockers & $49(86 \%)$ & $27(82 \%)$ & $22(92 \%)$ & 0.28 \\
\hline Angiotensin-converting enzyme inhibitor & $42(74 \%)$ & $25(77 \%)$ & $17(71 \%)$ & 0.68 \\
\hline Angiotensin receptor blockers & $12(21 \%)$ & $7(22 \%)$ & $5(21 \%)$ & 0.92 \\
\hline Digoxin & $10(17 \%)$ & $3(9 \%)$ & $7(29 \%)$ & 0.05 \\
\hline Spironolactone & $31(54 \%)$ & $16(48 \%)$ & $15(62 \%)$ & 0.29 \\
\hline \multicolumn{5}{|l|}{ Lead placement } \\
\hline Posterior & $30(53 \%)$ & $16(48 \%)$ & $14(58 \%)$ & 0.46 \\
\hline Lateral & $27(47 \%)$ & $17(51 \%)$ & $10(42 \%)$ & 0.46 \\
\hline Anterior & 0 & - & - & - \\
\hline
\end{tabular}

myocardial infarction or previous revascularization. All patients provided informed consent. The study protocol conformed to the ethical guidelines of the 1975 Declaration of Helsinki and was approved by local ethics committee.

Patients underwent clinical examination, 12-lead electrocardiography, echocardiography at rest, and stress echocardiography including dobutamine stress echocardiography or exercise stress echocardiography within the week before biventricular pacing implantation. Echocardiography at rest was also performed within 24 hours after device placement. Acute responders to CRT were defined as presenting a $>15 \%$ increase in LV stroke volume. ${ }^{5}$ Follow-up clinical and echocardiographic examinations were obtained at 6 months. Long-term responders were defined by $\geq 15 \%$ decrease in LV end-systolic volume. ${ }^{15}$ Echocardiographic measurements were performed by 2 observers blinded to a patient's status using a Philips Sonos 5500 or 7500 instrument with a 2.5-MHz transducer (Philips Medical Systems, Amsterdam, The Netherlands) or a Vivid 7 imaging device (GE Vingmed Ultrasound, Horten, Norway). LV volumes and ejection fraction were measured using the modified biplane Simpson rule. LV stroke volume was calculated by multiplying the LV outflow tract area by the LV outflow tract velocity-time integral measured by pulse-wave Doppler. Proximal isovelocity surface area was used to assess MR severity and to measure effective regurgitant orifice (ERO) area and regurgitant volume. ${ }^{16}$ Aortic and pulmonary Doppler flows were recorded in the pulse mode from the apical 4-chamber view and parasternal short-axis view, respectively. Aortic and pulmonary ejection delays were defined as the delay between onset of the QRS complex on the surface electrocardiogram and onset of aortic and pulmonary waves. Interventricular delay was defined as the time difference between aortic and pulmonary electromechanical delay. ${ }^{17}$ Tissue Doppler imaging was performed in the pulse-wave Doppler mode from apical views to assess longitudinal myocardial regional function, analyzing the septal, inferior, lateral, anterior, and posterior walls. ${ }^{17} \mathrm{Ve}-$ locity profiles were recorded with a sample volume placed in the middle of the basal segment of each wall. Gain and filters were adjusted as needed to eliminate background noise and to allow a clear tissue signal. Tissue Doppler imaging signals were recorded at a sweep of $100 \mathrm{~mm} / \mathrm{s}$. Electromechanical delay, defined as the delay between onset of the QRS complex on the surface electrocardiogram and onset of the systolic tissue Doppler imaging wave, were measured. Intraventricular asynchronism was defined as the time difference between the shortest and longest electromechanical delays among the $5 \mathrm{LV}$ walls. Thirty-four patients underwent dobutamine stress echocardiography with a lowdose infusion; they received dobutamine $5,10,15$, and 20 $\mu \mathrm{g} / \mathrm{kg} / \mathrm{min}$ in 3-minute stages, with echocardiographic images recorded at each stage. ${ }^{18}$ Heart rate and blood pressure were monitored during each stage. Criteria for stopping the dobutamine infusion included (1) hypotension (systolic blood pressure $<90 \mathrm{~mm} \mathrm{Hg}$ ), (2) angina, (3) significant arrhythmias (atrial fibrillation, bigeminy, ventricular tachycardia), and (4) obtainment of $85 \%$ maximal predicted heart rate. Twenty-three patients underwent stress echocardiography. A symptom-limited graded bicycle exercise test was performed in a semisupine position on a tilting exercise table. After an initial workload of $25 \mathrm{~W}$ maintained for 2 minutes, the workload was increased every 2 minutes by 25 $\mathrm{W}$. Blood pressure and a 12-lead electrocardiogram were recorded every 2 minutes; 2-dimensional echocardiographic recordings were made throughout the test. During stress echocardiography (exercise or dobutamine), regional wall motion score index was assessed using the 16-segment model recommended by the American Society of Echocardiography. ${ }^{19}$ Thus, a normal or hyperkinetic segment was graded as 1 , hypokinetic as 2, akinetic as 3, and dyskinetic as 4 . Peak stress images showing maximum augmentation 
Table 2

Echocardiographic data

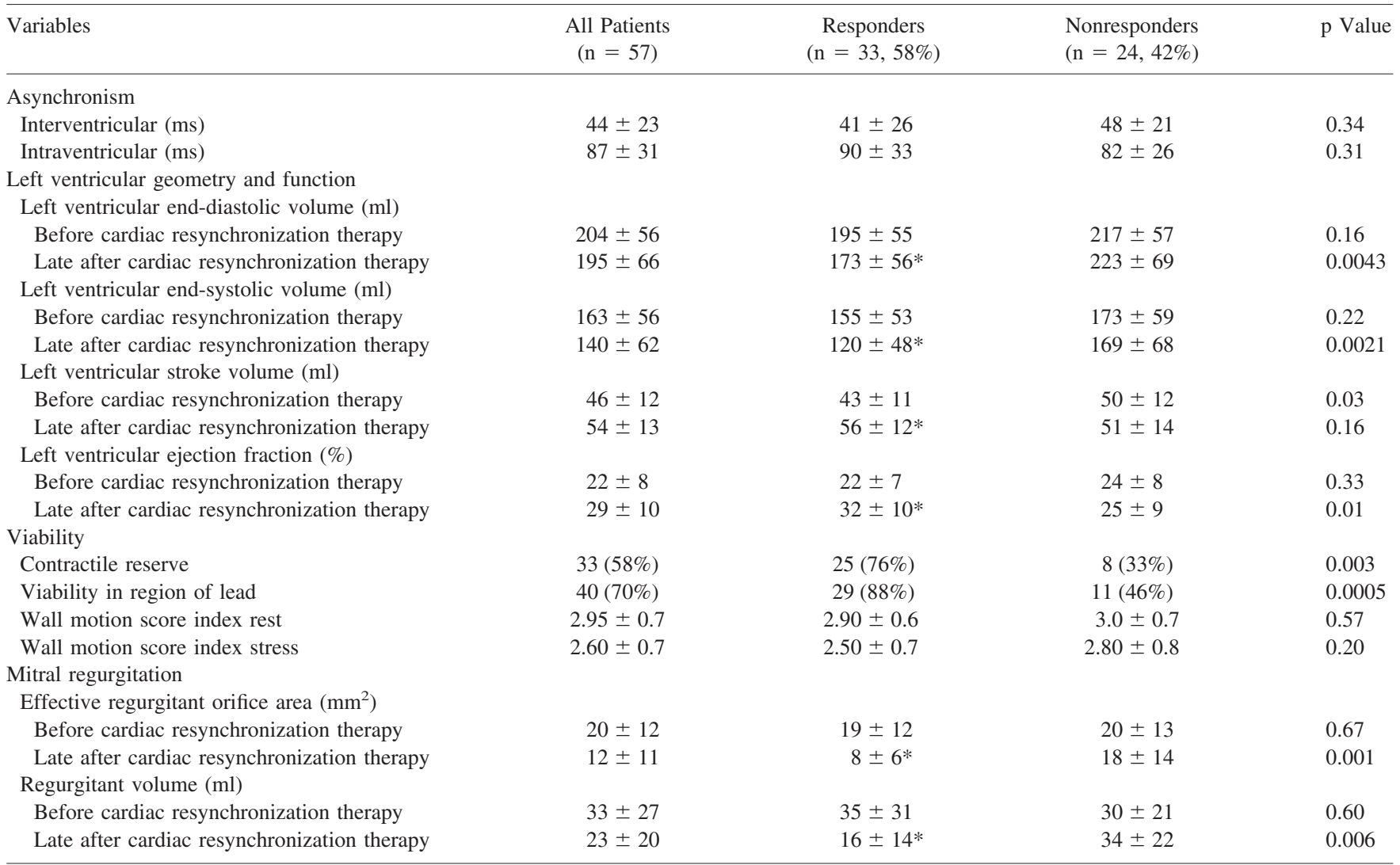

* Significant difference $(\mathrm{p}<0.05)$ between data before and late after cardiac resynchronization therapy.

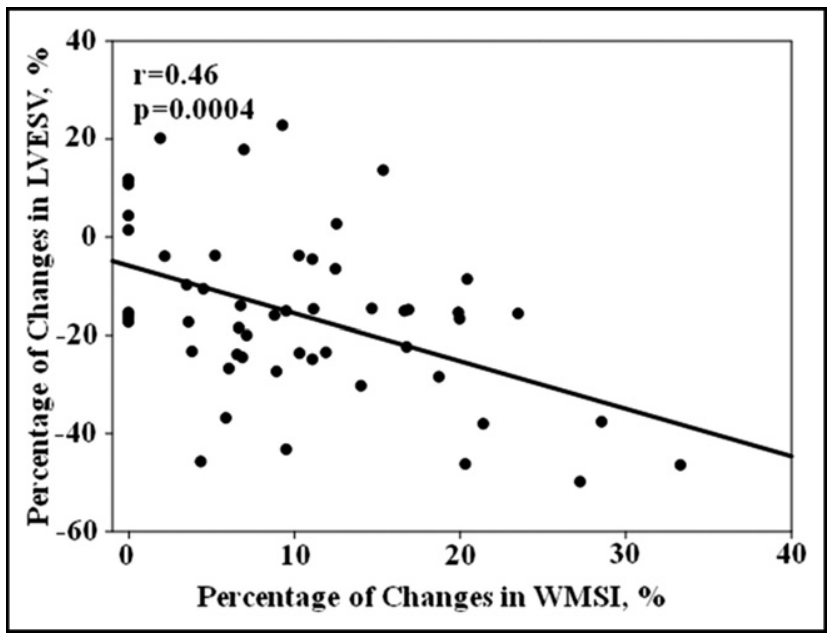

Figure 1. Correlation between percent changes in LV end-systolic volume (LVESV) and percent changes in wall motion score index (WMSI).

of the wall motion score index were compared to baseline images. A segment was considered to have contractile reserve if the wall motion score index improved by $\geq 1$ grade. Viability in the region of the LV pacing lead was defined as the presence of viability in 2 contiguous segments. Presence of $\mathrm{LV}$ contractile reserve was defined as an improvement of $\geq 0.20$ in wall motion score index (at rest/stress). ${ }^{18} \mathrm{~A}$ coronary sinus venogram was obtained using a balloon cathe- ter, followed by insertion of the LV pacing lead (Guidant Corp., St. Paul, Minnesota; or Medtronic, Inc., Minneapolis, Minnesota) in the coronary sinus. The preferred position was a lateral or posterolateral vein. Right atrial and ventricular leads were positioned conventionally. All leads were connected to a dual-chamber biventricular pacing (Guidant Corp. or Medtronic, Inc.). After successful implantation, echocardiography was used to optimize the atrioventricular delay to maximize LV filling time. Interventricular pacing interval was set to a default value (VV $0 \mathrm{~ms}$ ). One day after implantation, the LV lead position was assessed from a chest $\mathrm{x}$-ray, using frontal and lateral views (scored anterior, lateral, or posterior). ${ }^{20}$

Results are expressed as mean $\pm \mathrm{SD}$ or number (percentage). Baseline data of responders versus nonresponders were compared for statistical significance using $t$ test, chisquare test, or Fisher's exact test as appropriate. Echocardiographic data at baseline and after CRT were compared within groups using paired $t$ test. Linear regression analyses were used to evaluate the relation between CRT response echocardiographic data.

\section{Results}

Table 1 presents baseline characteristics of the population before CRT. Device implantation was successful in all patients and 1 patient developed pneumothorax after CRT implantation. LV pacing thresholds were not different be- 


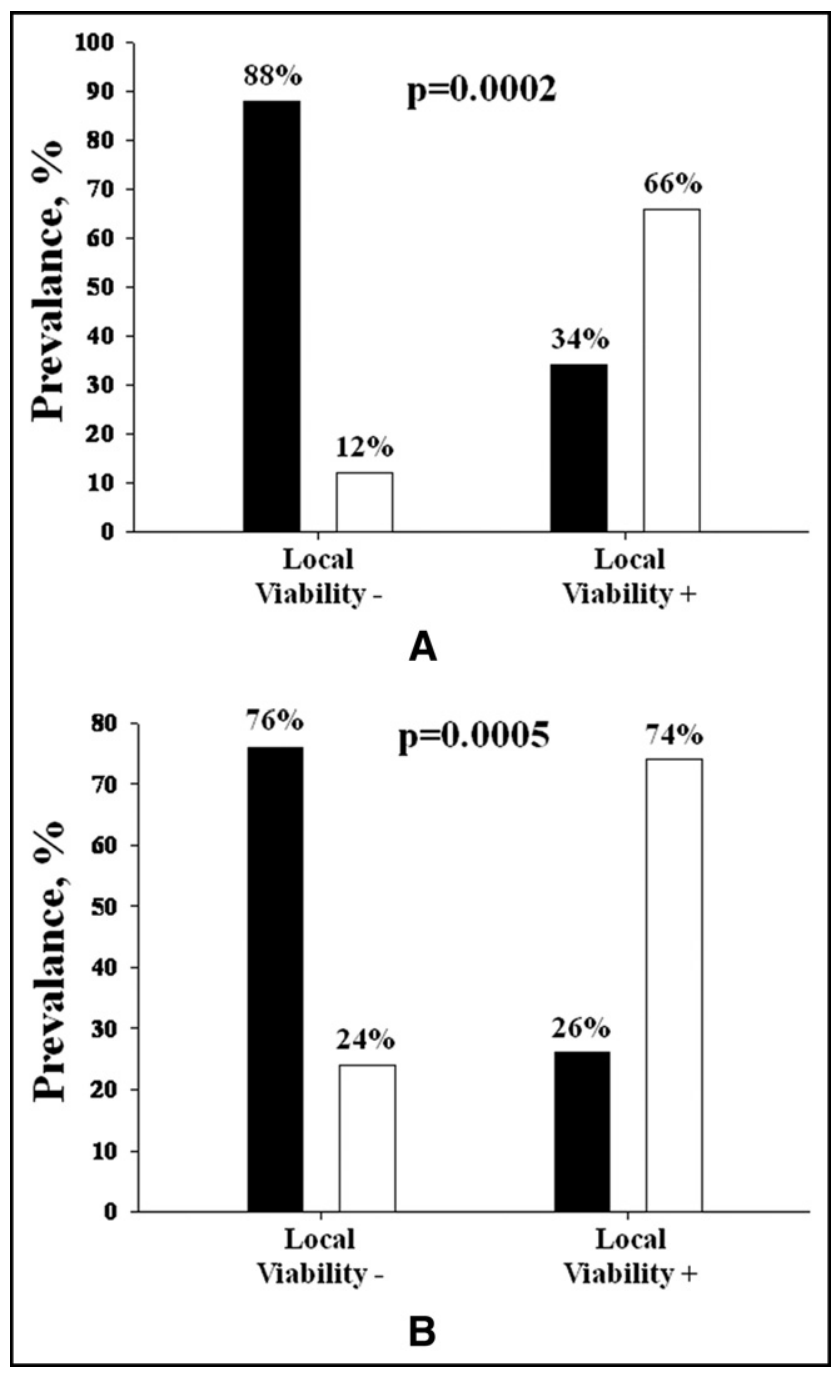

Figure 2. Percentage of $(A)$ acute and $(B) 6$ months responders (white bars) and non responders (black bars) to CRT based on the presence or absence of viability in the region of the pacing lead.

tween responders and nonresponders $(1.18 \pm 0.70$ vs $1.75 \pm$ $0.5, \mathrm{p}=0.17$ ). During stress echocardiography, no patients demonstrated angina or electric or regional wall motion modification at peak stress suggesting ischemia. The day after CRT implantation, 28 patients $(49 \%)$ were acute responders (increased LV stroke $\geq 15 \%$ ), whereas at 6 months 33 patients $(58 \%)$ were classified as long-term responders (decrease in LV end-systolic volume $\geq 15 \%$ ). Baseline LV volumes, LV ejection fraction, LV wall motion score index at rest and stress, MR severity, interventricular mechanical delay, and LV asynchrony were not significantly different between long-term responders and nonresponders (Table 2). Nonresponder patients had larger baseline LV stroke volume than responders, but after CRT this difference was no longer significant. As expected, LV geometry and function and MR severity were significantly improved in responders.

All patients completed the stress echocardiographic protocol without complications. Absolute changes $(r=0.32$, $\mathrm{p}=0.01)$ and percent changes $(\mathrm{r}=0.35, \mathrm{p}=0.008)$ in LV stroke volume 24 hour after CRT implantation were directly related to changes in wall motion score index. Percent

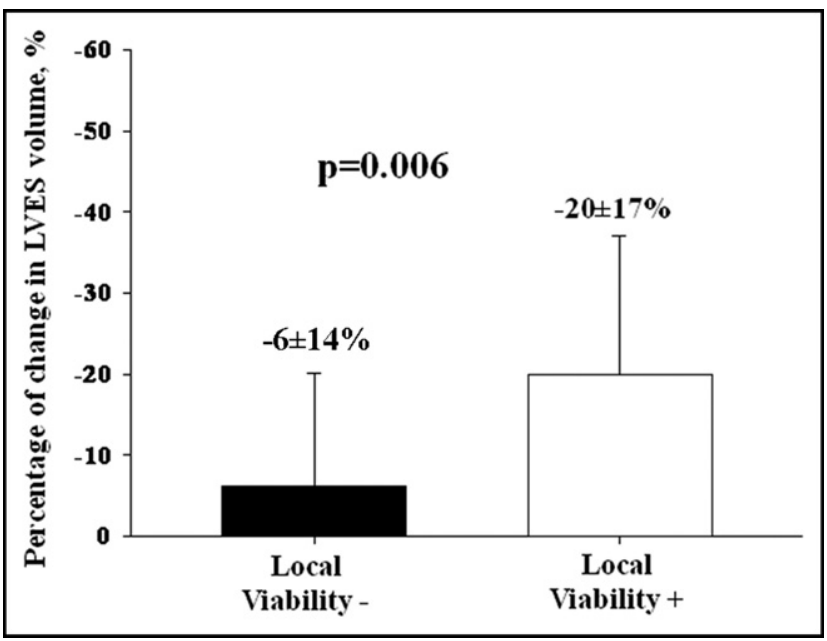

Figure 3. Changes in LVES volume after CRT in responders (white bar) and nonresponders (black bar) based on presence of viability in the region of the pacing lead. Abbreviation as in Figure 1.

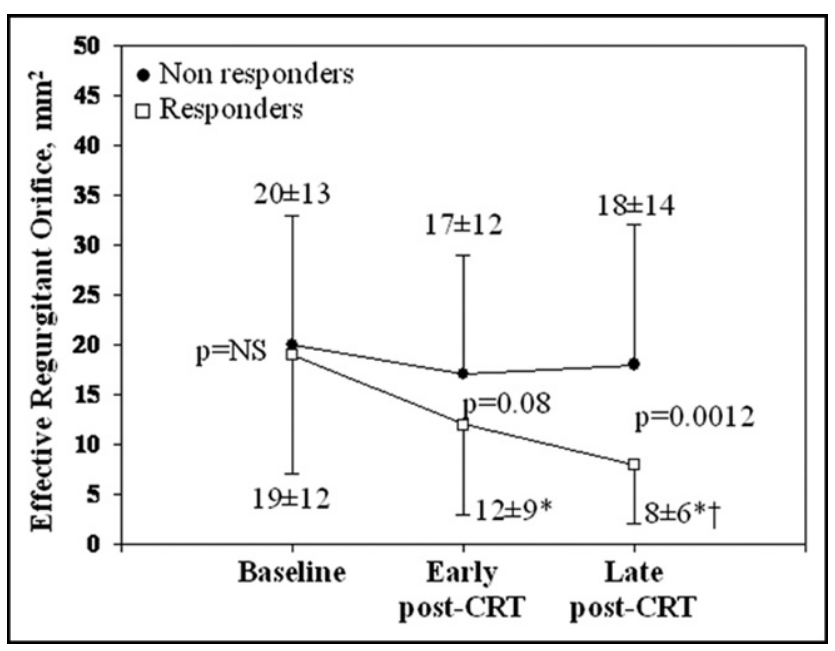

Figure 4. ERO area at baseline, soon after CRT (i.e., $<48$ hours) and at 6 months after CRT in responders and nonresponders. *Significant difference from baseline; ’ significant difference from soon after CRT.

changes in LV end-systolic volume at 6 months were significantly correlated with the peak wall motion score index $(\mathrm{r}=0.49, \mathrm{p}=0.0002)$ and percent changes in wall motion score index $(r=0.46, p=0.0004)$ during stress echocardiography (Figure 1). Similar correlations were observed in ERO decrease at 6 months $(\mathrm{r}=0.36, \mathrm{p}=0.007)$. Contractile reserve was present in 33 patients $(58 \%)$. Acute and long-term responders had a higher prevalence of contractile reserve than nonresponders $(74 \%$ vs $43 \%, p=0.02 ; 76 \%$ vs $33 \%, \mathrm{p}=0.003$, respectively; Table 2 ). Presence of contractile reserve had, respectively, a sensitivity and specificity to predict acute (74\% and 57\%) and long-term (75\% and $65 \%$ ) responses to CRT. Presence of viability in the region of the pacing lead was more frequent in acute and long-term responders than in nonresponders (Figure 2). LV lead positioned in a region with viability was associated with greater LV end-systolic volume decrease $(-6 \pm 14 \%$ vs $-20 \pm 17 \%, p=0.006$; Figure 3). Viability in the region of the pacing lead predicted acute and long-term responses 


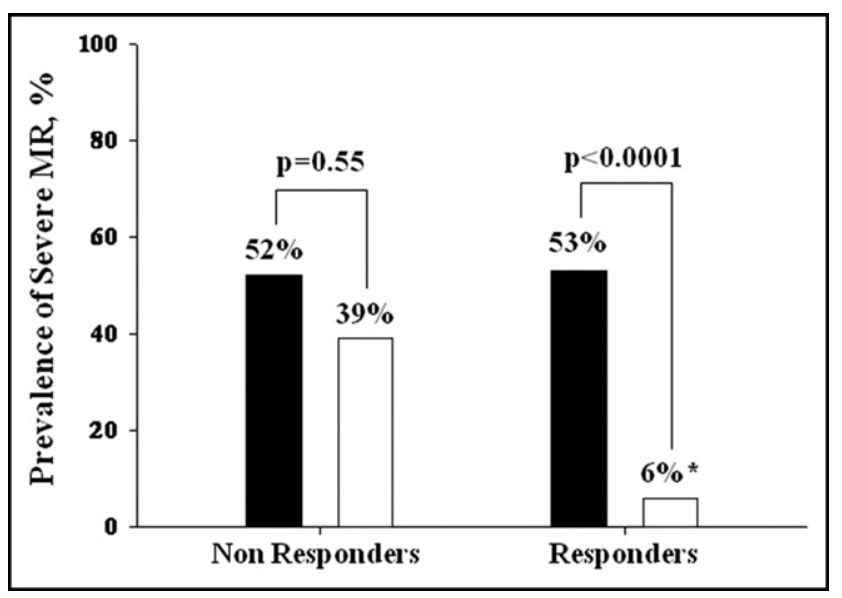

Figure 5. Prevalence of severe MR at baseline (black bars) and at 6 months (white bars) between responders and nonresponders. *Significant difference from nonresponders.

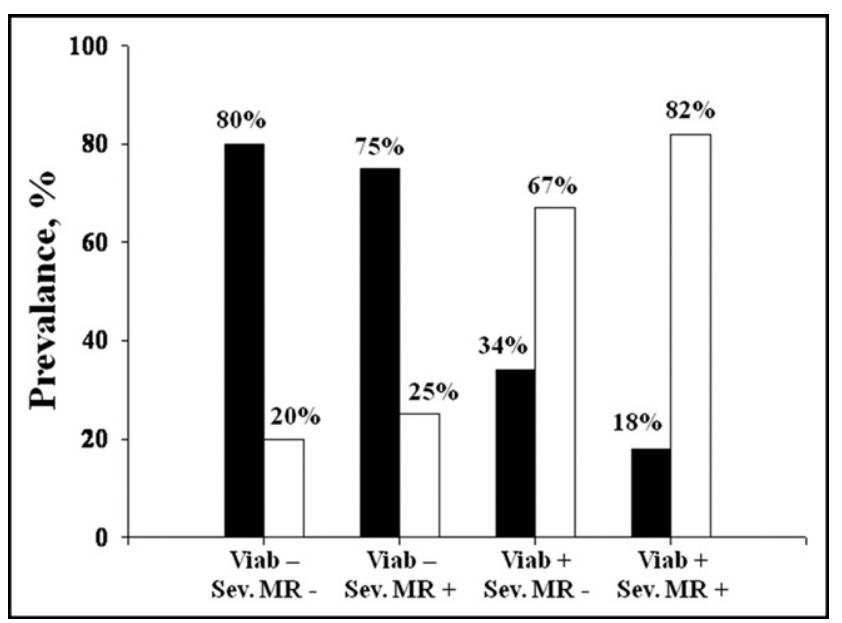

Figure 6. Percentage of responders (white bars) versus nonresponders (black bars) to CRT according to presence of viability in the region or the pacing lead (viab \pm ) and the presence of severe MR (ERO $\geq 20 \mathrm{~mm}^{2}$ ).

with sensitivities of $93 \%$ and $88 \%$ and specificities of $54 \%$ and $57 \%$, respectively. There was no significant difference in baseline MR severity and prevalence of severe MR between groups (Figures 4 and 5). ERO and regurgitant volume were significantly decreased after CRT in responders, whereas there was no significant change in nonresponders (Table 2). In responders, ERO was decreased by $58 \%$ (from $19 \pm 12 \mathrm{~mm}^{2}$ to $8 \pm 6 \mathrm{~mm}^{2}, \mathrm{p}=0.001$ ) at 6 months (Figure 5). Responders had a lower prevalence of severe MR after CRT than nonresponders. There was good correlation between changes in ERO and changes in LV end-systolic volume $(r=0.44, p=0.0015)$. Long-term responders were more frequent in patients with the combined presence of severe MR and viability in the region of the pacing lead (Figure 6).

\section{Discussion}

In patients with ischemic LV dysfunction and significant LV dyssynchrony, response to CRT is modulated by several factors. In the present study, we confirm that acute and long-term benefits to CRT depend not only on the presence of LV dyssynchrony but also on the extent of residual myocardial viability and severity of MR. A direct relation existed between extent of myocardial contractile recruitment during stress echocardiography and extent of LV reverse remodeling. Conversely, absence of contractile reserve particularly in the region of the pacing lead is likely associated with less or no decrease in LV end-systolic volume after CRT.

A range of echocardiographic and clinical variables have been proposed as possible markers of nonresponse, including cause of the underlying heart disease. ${ }^{12,13,21-24}$ It is still a point of discussion whether the ischemic origin of the disease is a predictor of nonresponse. Previous studies have shown that having heart failure from ischemic origin particularly if associated with severe MR is a predictor of lack of response to CRT. ${ }^{12-14}$ In the same line Sutton et $\mathrm{al}^{15}$ demonstrated that reverse remodeling after CRT occurred mainly in nonischemic patients. Conversely, Molhoek et $\mathrm{al}^{21}$ showed that the underlying cause of heart failure was not related to CRT response. In a study including 106 patients, Vidal et $\mathrm{al}^{22}$ observed at 12-month follow-up that patients with LV systolic dysfunction and left bundle branch block treated by CRT showed clinical improvements and reverse remodeling irrespective of the cause of their cardiopathy. This discrepancy between studies suggests that response to CRT is a multifactor process that may include severity of intraventricular asynchrony, presence and localization of LV viability, and presence and severity of MR.

In our study all patients had heart failure from ischemic origin and significant intraventricular asynchronism $(\geq 50$ ms, mean $87 \pm 31$ ) that was above the cut-off value of $\geq 65$ ms suggested in previous studies as having the best combination of sensitivity and specificity to predict acute and long-term CRT responses. ${ }^{5}$ In studies including patients with systolic dysfunction of ischemic and nonischemic origins and significant LV asynchrony, LV remodeling at 6 months has been usually $\geq 70 \%$. $^{14,25}$ In accordance with previous studies, our results suggest that in a population of patients with heart failure of ischemic origin, ${ }^{12,23} \mathrm{LV}$ remodeling at 6 months is less frequent (i.e., 58\%) than in patients with other heart failure causes. Nonetheless, our study demonstrated that in the presence of significant asynchrony and viability in the region of the pacing lead, longterm LV remodeling in patients with ischemic cardiomyopathy is observed in $74 \%$ of patients.

By decreasing dyssynchrony, CRT has the potential to decrease ischemic MR. Effects of CRT on ischemic MR may occur early and late after CRT. CRT acutely decreases MR by increasing the closing force and decreasing the tethering forces acting on the mitral valve apparatus. CRT also decreases MR by co-ordinating contraction of papillary muscles. ${ }^{11}$ Long-term LV remodeling may explain the subsequent MR decrease during follow-up. Pooled data from 5 major studies of $>350$ patients with implanted biventricular devices, followed for $>6$ months, showed a decrease of MR by $30 \%$ to $40 \% .^{13}$ In our study ERO was decreased by $58 \%$ at 6 months. The main ERO decrease occurred at 24 hours after CRT implantation, suggesting that acute resynchronization of the papillary muscle and an improved closing force are the main mechanisms explaining this impressive 
early MR decrease (Figure 4). The influence of MR severity on CRT response is conflicting. Some investigators shown that patients with severe MR have a lesser chance of showing improvement with CRT. ${ }^{12-14}$ However, these studies included a limited number of patients. In the Cardiac Resynchronization in Heart Failure (CARE-HF) study, a randomized trial including a large number of patients, it was conversely shown that patients who showed no improvement were likely to have no significant MR compared to responders. ${ }^{26}$ The results of the present study confirm and extend this observation. Of interest, responders were more frequent $(82 \%)$ in the subgroup of patients with residual viability in the region of the pacing lead and severe MR.

In patients with severe decreased LV function, identification of contractile reserve during stress echocardiography has been shown to provide important prognostic information in patients with heart failure. More specifically in patients referred to CRT, few investigators have reported that the presence of viability in the region of the pacing lead might modulate the response to CRT. ${ }^{27,28}$ Our data are in line with these considerations. Extent of LV global contractile reserve was related to percent acute changes in forward stroke volume and to extent of decrease in end-systolic volume. The role of residual viability in the stimulated LV area has been recently highlighted. Patients with transmural scar in the posterolateral region as assessed by contrastenhanced magnetic resonance imaging showed not improvement under stimulation. ${ }^{27}$ Similarly, absence of contractile reserve in the region of the LV pacing as manifested by no significant changes in wall motion score during stress echocardiography precludes LV reverser remodeling in most patients. ${ }^{29,30}$ In line with these data, we found that responders to CRT showed greater wall motion improvement in the region of the LV pacing lead during stress compared to nonresponders. Furthermore, these data indicate that a substantial amount of recruitable myocardium is needed to obtain improvement in LV function after CRT.

These results should be regarded cautiously and some limitations should be underlined. Although the difference was not statistically different, more nonresponders took digoxin and spironolactone than responders. Therefore, because of the sample $(n=57)$ and heterogeneity of the population studied, those data should be confirmed by suitably powered clinical trials that are undoubtedly needed. Also, dyssynchrony was defined by longitudinal tissue Doppler imaging using a cut-off value of $50 \mathrm{~ms}$ as the inclusion criterion. Combining longitudinal and radial dyssynchrony indexes as inclusion criteria could have been helpful in choosing a more homogenous population prone to CRT response.

1. Cazeau S, Leclercq C, Lavergne T, Walker S, Varma C, Linde C, Garrigue S, Kappenberger L, Haywood GA, Santini M, Bailleul C, Daubert JC. Effects of multisite biventricular pacing in patients with heart failure and intraventricular conduction delay. $N$ Engl $J$ Med 2001;344:873-880.

2. Abraham WT, Fisher WG, Smith AL, Delurgio DB, Leon AR, Loh E, Kocovic DZ, Packer M, Clavell AL, Hayes DL, Ellestad M, Tupp RJ, Underwood J, Pickering F, Truex C, McAtee P, Messenger J. MIRACLE Study Group. Multicenter InSync Randomized Clinical Evaluation. Cardiac resynchronization in chronic heart failure. N Engl J Med 2002;346:1845-1853.
3. Cleland JG, Daubert JC, Erdmann E, Freemantle N, Gras D, Kappenberger L, Tavazzi L. The effect of cardiac resynchronization on morbidity and mortality in heart failure. N Engl J Med 2005;352:15391549 .

4. Tournoux FB, Alabiad C, Fan D, Chen AA, Chaput M, Heist EK, Mela T, Mansour M, Reddy V, Ruskin JN, Picard MH, Singh JP. Echocardiographic measure of acute haemodynamic response after cardiac resynchronization therapy predicts long term clinical outcome. Eur Heart J 2007;28:1143-1148.

5. Gorcsan J III, Kanzaki H, Bazaz R, Dohi K, Schwartzman D. Usefulness of echocardiographic tissue synchronization imaging to predict acute response to cardiac resynchronization therapy. Am J Cardiol 2004;93:1178-1181.

6. Breithardt OA, Sinha AM, Schwammenthal E, Bidaoui N, Markus $\mathrm{KU}$, Franke A, Stellbrink C. Acute effects of cardiac resynchronization therapy on functional mitral regurgitation in advanced systolic heart failure. J Am Coll Cardiol 2003;41:765-770.

7. Kanzaki H, Bazaz R, Schwartzman D, Dohi K, Sade LE, Gorcsan J III. A mechanism for immediate reduction in mitral regurgitation after cardiac resynchronization therapy. J Am Coll Cardiol 2004;44:16191625.

8. Vinereanu D, Turner MS, Bleasdale RA, Mumford CE, Cinteza M, Frenneaux MP, Fraser AG. Mechanisms of reduction of mitral regurgitation by cardiac resynchronization therapy. J Am Soc Echocardiogr 2007;20:54-62.

9. Karvounis HI, Dalamaga EG, Papadopoulos CE, Karamitsos TD, Vassilikos V, Paraskevaidis S, Styliadis IH, Parharidis GE, Louridas GE. Improved papillary muscle function attenuates functional mitral regurgitation in patients with dilated cardiomyopathy after cardiac resynchronization therapy. J Am Soc Echocardiogr 2006;19:1150-1157.

10. Agricola E, Oppizzi M, Galderisi M, Pisani M, Meris A, Pappone C, Magonato A. Role of regional mechanical dyssynchrony as a determinant of functional mitral regurgitation in patients with left ventricular systolic dysfunction. Heart 2006;92:1390-1395.

11. Madaric J, Vanderheyden M, Van Laethem C, Verhamme K, Feys A, Goethals M, Verstreken S, Geelen P, Penicka M, De Bruyne B, Bartek J. Early and late effects of cardiac resynchronization therapy on exercise-induced mitral regurgitation: relationship with left ventricular dyssynchrony, remodeling and cardiopulmonary performance. Eur Heart J 2007;28:2134-2141.

12. Diaz-Infante E, Mont L, Leal J, García-Bolao I, Fernández-Lozano I, Hernández-Madrid A, Pérez-Castellano N, Sitges M, Pavón-Jiménez R, Barba J, Cavero MA, Moya JL, Pérez-Isla L, Brugada J. Predictors of lack of response to resynchronization therapy. Am J Cardiol 2005; 95:1436-1440.

13. Vinereanu D. Mitral regurgitation and cardiac resynchronization therapy. Echocardiography 2008;25:1155-1166.

14. Cabrera-Bueno F, García-Pinilla JM, Peña-Hernández J, Jiménez-Navarro M, Gómez-Doblas JJ, Barrera-Cordero A, Alzueta-Rodriguez J, de Teresa-Galván E. Repercussion of functional mitral regurgitation on reverse remodelling in cardiac resynchronization therapy. Europace 2007:9:757-761.

15. Sutton MG, Plappert T, Hilpisch KE, Abraham WT, Hayes DL, Chinchoy E. Sustained reverse left ventricular structural remodeling with cardiac resynchronization at one year is a function of etiology: quantitative Doppler echocardiographic evidence from the Multicenter InSyc Randomized Clinical Evaluation (MIRACLE). Circulation 2006; 113:266-272.

16. Zoghbi WA, Enriquez-Sarano M, Foster E, Grayburn PA, Kraft CD, Levine RA, Nihoyannopoulos P, Otto CM, Quinones MA, Rakowski $\mathrm{H}$, Stewart WJ, Waggoner A, Weissman NJ. Recommendations for evaluation of the severity of native valvular regurgitation with twodimensional and Doppler echocardiography. J Am Soc Echocardiogr 2003;16:777-802.

17. Bader H, Garrigue S, Lafitte S, Reuter S, Jaïs P, Haïssaguerre M, Bonnet J, Clementy J, Roudaut R. Intra-left ventricular electromechanical asynchrony. A new independent predictor of severe cardiac events in heart failure patients. $J$ Am Coll Cardiol 2004:43:248-256.

18. Ciampi Q, Pratali L, Citro R, Piacenti M, Villari B, Picano E. Identification of responders to cardiac resynchronization therapy by contractile reserve during stress echocardiography. Eur J Heart Fail 2009; 11:489-496.

19. Schiller NB, Shah PM, Crawford M, DeMaria A, Devereux R, Feigenbaum H, Gutgesell H, Reichek N, Sahn D, Schnittger I, Silverman NH, 
Tajik AJ. Recommendations for quantitation of the left ventricle by two-dimensional echocardiography. $J$ Am Soc Echocardiogr 1989;2:358-367.

20. Butter C, Auricchio A, Stellbrink C, Fleck E, Ding J, Yu Y, Huvelle E, Spinelli J. Effect of resynchronization therapy stimulation site on the systolic function of heart failure patients. Circulation 2001;104: 3026-3029.

21. Molhoek SG, Bax JJ, van Erven L, Bootsma M, Boersma E, Steendijk $\mathrm{P}$, van der Wall EE, Schalij MJ. Comparison of benefits from cardiac resynchronization therapy in patients with ischemic cardiomyopathy versus idiopathic dilated cardiomyopathy. Am J Cardiol 2004;93:860863.

22. Vidal B, Sitges M, Delgado V, Mont L, Díaz-Infante E, Azqueta M, Paré C, Tolosana JM, Berruezo A, Tamborero D, Roig E, Brugada J. Influence of cardiopathy etiology on responses to cardiac resynchronisation therapy. Rev Esp Cardiol 2007;60:1264-1271.

23. Mangiavacchi M, Gasparini M, Faletra F, Klersy C, Morenghi E, Galimberti P, Genovese L, Regoli F, De Chiara F, Bragato R, Andreuzzi B, Pini D, Gronda E. Clinical predictors of marked improvement in left ventricular performance after cardiac resynchronization therapy in patients with chronic heart failure. Am Heart J 2006; 151(suppl):477.e1-477.e6.

24. Bleeker GB, Mollema SA, Holman ER, Van de Veire N, Ypenburg C, Boersma E, van der Wall EE, Schalij MJ, Bax JJ. Left ventricular resynchronization is mandatory for response to cardiac resynchronization therapy: analysis in patients with echocardiographic evidence of left ventricular dyssynchrony at baseline. Circulation 2007;116: $1440-1448$
25. Yu CM, Bleeker GB, Fung JW, Schalij MJ, Zhang Q, van der Wall EE, Chan YS, Konbg SL, Bax JJ. Left ventricular reverse remodeling but not clinical improvement predict long-term survival after cardiac resynchronization therapy. Circulation 2005;112:1580-1586.

26. Cleland J, Freemantle N, Ghio S, Fruhwald F, Shankar A, Marijanowski M, Verboven Y, Tavazzi L. Predicting the long-term of cardiac resynchronization therapy on mortality from baseline variables and the early response. A report from the CARE-HF (Cardiac Resynchronization in Heart Failure) trial. J Am Coll Cardiol 2008;52:438445 .

27. Bleeker GB, Kaandorp TAM, Lamb JH, Boersma E, Steendijk P, de Roos A, van der Wall EE, Schalij MJ, Bax JJ. Effect of posterolateral scar tissue on clinical and echocardiographic improvement after cardiac resynchronization therapy. Circulation 2006;113:969-976.

28. Lim P, Bars C, Mitchell-Hegg L, Roiron C, Elbaz N, Hamdaoui B, Lellouche N, Dubois-Randé JL, Guéret P. Importance of contractile reserve for CRT. Europace 2007;9:739-743.

29. Sénéchal M, Lancellotti P, Garceau P, Champagne J, Dubois M, Magne J, Blier L, Molin F, Philippon F, Dumesnil JG, Pierard L, O'Hara G. Usefulness and limitation of dobutamine stress echocardiography to predict acute response to cardiac resynchronization therapy. Echocardiography 2010;27:50-57.

30. Lancelloti P, Sénéchal M, Moonen M, Donal E, Magne J, Nellessen E, Attena E, Cosyns B, Melon P, Piérard L. Myocardial contractile reserve during exercise predicts left ventricular reverse remodeling after cardiac resynchronization therapy. Eur J Echocardiogr 2009;10: $663-668$. 